\title{
Improving the machining accuracy of low-rigid details on the computer numerically controlled lathe machine
}

\section{Andrey Pavlovich Starostin ( $\sim$ ap-star@yandex.ru )}

\section{Original Article}

Keywords: shaft processing, turning process, computer numerically controlled machine, shape defect, machining accuracy, shaft deformation, cutting force

Posted Date: May 8th, 2020

DOI: https://doi.org/10.21203/rs.3.rs-26860/v1

License: (c) (1) This work is licensed under a Creative Commons Attribution 4.0 International License.

Read Full License 


\title{
Improving the machining accuracy of low-rigid details on the computer numerically controlled lathe machine
}

\author{
Andrey Starostin
}

\begin{abstract}
The article describes a method for calculating the motion trajectory of a turning tool on a numerically controlled machine to compensate elastic strain when processing a raw part. When sharpening rotary bodies with low rigidity, elastic strain occurs under the action of the cutting force Py, that has a negative impact on the accuracy of the machined surface. As a result, a fault appears in the barrel-shaped and saddle-shaped form, or a combination of these faults, depending on the rigidity of the machine and its individual parts. Based on a mathematical model of elastic strain with a constant cutting depth, this fault had been determined, which was subsequently compensated by the use of a modified trajectory. Thus, when processing, the required diameter is obtained with minimal defects, which in turn will have a positive impact on the reduction of the processing steps of the entire detail, as well as the reduction of mold defect and improving the quality of part process.
\end{abstract}

Keywords: shaft processing, turning process, computer numerically controlled machine, shape defect, machining accuracy, shaft deformation, cutting force

\section{Introduction}

In modern engineering, about $30 \%$ of parts are represented by shafts, axles, torsions and etc. A significant proportion of these parts has a low rigid design (the ratio of length to diameter is 10:1 or more), which leads to their deformation when processing on lathes $[1,2]$. That causes a form defect (barrel-shaped, saddle-shaped forms and waviness). To increase the accuracy of processing low rigid shafts, several methods are usually used:

1 Using special devices: lunettes, devices that create tensile deformations, etc. $[3,4,5]$;

2 Changing the feed along the length of the shaft when processing on the numerically controlled machine (CNC) [6];

3 Reducing the cutting depth throughout the passage [7].

Any modern production is aimed at increasing productivity at minimal cost, so using the first two methods is not practical, because the first method causes some additional costs for purchasing additional devices and their implementation on the lathe. The second and third methods cause a decrease in productivity because of an increase in the number of passes or an increase in the passage time when the

Correspondence: andrey.starostin@urfu.ru

Ural Federal University named after the first President of Russia B.N.

Yeltsin, 59 Krasnogvardeyskaya st., Nizhny Tagil, Russia

Full list of author information is available at the end of the article feed changes. When changing the feed during processing on a CNC machine lathe, steps are formed on the part surface in the places where the tool is standing, which worsens the roughness of the processed surface [8]. Another option for controlling the accuracy of processing on a CNC lathe machine is the introduction of preliminary pre-setting of the tool path $[9,10]$.

When conduct a research on this method, the following tasks were set:

1 The developing a mathematical model of the shaft processing along a predistorted path;

2 Verificating the obtained mathematical model for the achieved accuracy and surface roughness during processing.

\section{Estimated dependences of elastic strain}

The deformation of the technological system when basing a part with a constant profile length in thecenters is determined by the known dependence [11].

$$
\begin{array}{r}
y=P_{y}\left[\mu \frac{x^{2}(1-x)^{2}}{3 E J L}+\left(1-\frac{x}{l}\right)^{2} \omega_{h s}\right]+\ldots \\
+P_{y}\left[\left(\begin{array}{l}
x^{2} \\
l
\end{array}\right) \omega_{t s}+\omega_{c}\right]
\end{array}
$$


where $x$ is the coordinate of the force along the length of the part from the headstock; $l$ - length of the part; $J$ - inertia moment of the part; $E$ - the elastic modulus of the material of the part; $\omega_{h s}, \omega_{t s}, \omega_{c}$ - compliance, respectively, of the front headstock, tailstock and caliper; $\mu$ - dynamic coefficient. The cutting force $P_{y}$ is determined by the equation [12]:

$$
P_{y}=10 C_{p} v^{u} S^{x} t^{z} K_{p}
$$

where $C_{p}$ is a constant coefficient; $v$ - cutting speed; $S$ feedrate; $t$ - cutting depth; $u, x, z$ - power coefficient, $K_{p}$ correction factor.

The deformation of the technological system when basing parts constant along the profile length is determined by the dependence [13]:

$$
y=P_{y} \omega_{t s},
$$

where $P_{y}$ is a component of the cutting force, and $\omega_{t s}$ is the flexibility of the technological system.

We should take into account the deformation of the technological system when processing low rigid parts in such a way when the deformation is compensated by changing the cutting depth. Then the cutting force will be determined by the equation:

$$
P_{y}=10 C_{p} v^{u} S^{x} K_{p}(t+y)^{z}
$$

So the magnitude of the elastic strain changes, which leads to a change in the cutting force and subsequent elastic strain, but with smaller deviations. Based on the analysis of the obtained data, the correction of the cutting depth can be limited by changing the amount of deformation at the nominal cutting depth increased by the ratio of the changed cutting force $P_{y}$ taking into account the deformation $y$ at a given initial $t$ on the cutting force at the nominal cutting depth.

We derive the equation based on Eqs. 2 and 4:

$$
i=\left(\frac{t+y}{t}\right)^{z}
$$

Finally, the cutting depth at a particular point will be calculated by the formula:

$$
t_{c a l c}=t+y i
$$

An example of the flexibility of a technological system when processing low rigid parts on lathe machines without the using special supporting devices (e.g. lunette) is shown graphically (Fig. 1)

Figure 2 illustrates the dependence of elastic strain for different processing approaches and the obtained diameter.

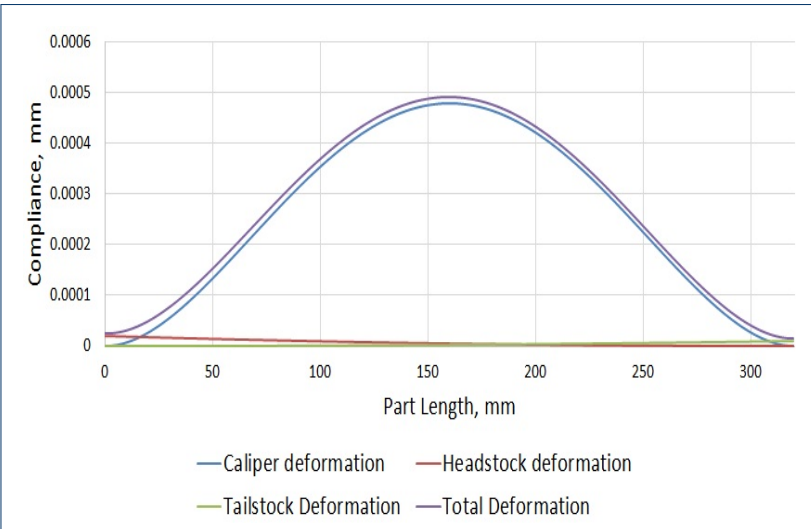

Figure 1 The schedule of deformations and flexibility of the technological system

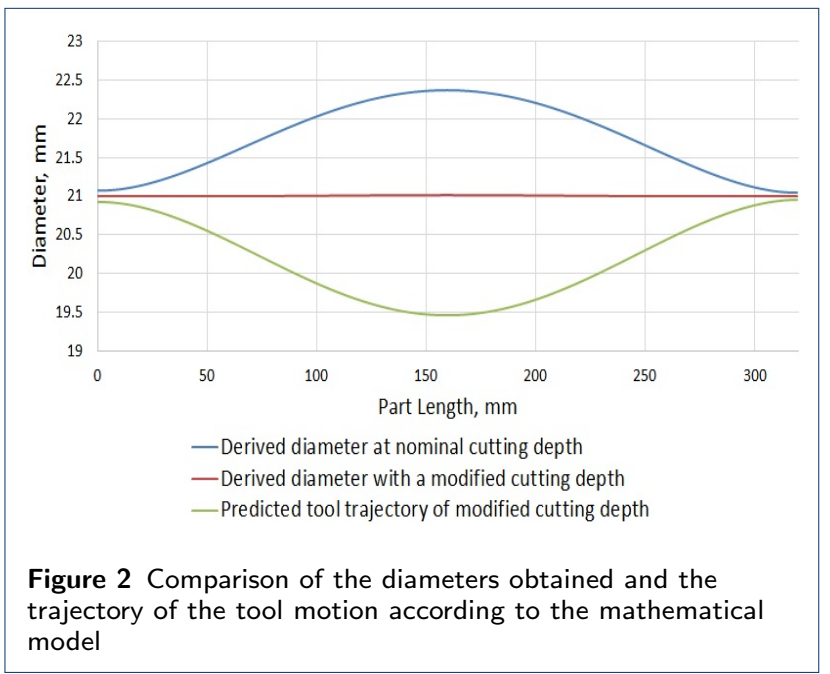

When a tool moves along a predistorted trajectory, it actually processes a diameter smaller than required. At this stage we take into account the elastic strain and the flexibility of the lathe machine, so we finally get a smooth shaft.

\section{Methodology and test results}

\section{Workpiece sizes: 320x28 mm}

Material: Steel 45

Material hardness: 36-39 HRC (based on measurements) The chemical composition is shown in Table 1 .

Testing the Eq. 4 required processing several shafts when basing center-center. Each shaft was machined in several passes from a diameter of 28 to a diameter of $21 \mathrm{~mm}$. Calculating the predistortion on the coordinate of the $X$ axis from the $Z$ coordinate requires using some Eqs. 2 and 6 . When processing the shaft, the working area was closed and there was no additional measuring equipment in the working area, so it was possible to supply Blaser Vasco 6000 cutting fluid. 
Table 1 Chemical composition Steel 45, \%

\begin{tabular}{lllllllll}
\hline $\mathrm{C}$ & $\mathrm{Si}$ & $\mathrm{Mn}$ & $\mathrm{Ni}$ & $\mathrm{S}$ & $\mathrm{P}$ & $\mathrm{Cr}$ & $\mathrm{Cu}$ & As \\
\hline $0.37-0.45$ & $0.17-0.37$ & $0.5-0.8$ & to 0.3 & to 0.04 & to 0.035 & to 0.25 & to 0.3 & to 0.08 \\
\hline
\end{tabular}

The results of the shafts measurements during machining Mitsubishi WNMG080404-MA with a cutter plate are shown in Table 2. Table 2 shows a clear dynamics for the appearance of barrel-shaped form in connection with the impact of the flexibility of the caliper, front and rear headstock when passing from one reference point of the program to another without using predistorted trajectory.

The subsequent analysis of the table shows the absence of a fault in the headstock, which is related to its minimal flexibility on the machine. This confirms the stiffness of the front headstock compared to the tailstock and caliper. When processing without predistortion in the coordinate 160 and $-140 \mathrm{~mm}$, there is a maximum deflection, which is natural. There will be a maximum error of plus of the finished product in this place. Thereby it forms a barrel shape. However, achieving the required tolerance in the shaft system needs another pass. Because of increasing cutting depth to the part middle and low rigid workpiece, the cutting forces increase, and thereby the ductility of the shaft also increases. This leads to an additional fault in the middle of the part. Technological heredity appears during processing, that causes increasing costs and using additional methods to improve the accuracy of the product.

When processing by predistortion, decreasing the error by $42-50 \%$ is observed under similar conditions and diameters of processing compared to turning the shaft in a straight line. The error changes direction and receives a negative value related to the nominal size during processing. If the maximum limit deviation is indicated as a plus, then we should take this into account when calculating the predistorted trajectory, and after that we can proceed from the maximum permissible shaft diameter. The resulting roughness is not more than $R_{a} 1.6 \mu \mathrm{m}$.

Figure 3 shows a slight increase of the error with an increase in the ratio of length to diameter when processing along a predistorted trajectory. These changes are natural, because the shaft becomes more malleable to the middle and bends more, but at the same time its error is much less compared with passes along a straight trajectory.

The results were similar. Moreover, one of the shafts has an error along a pre-distorted trajectory on a diameter of 30 $\mathrm{mm}$. The maximum error was $9 \mu \mathrm{m}$ over the entire length. It is considered to be a fairly high result. It was possible to achieve such accuracy by preliminary measuring the rigidity of all lathe machine elements with the subsequent substitution of these values in Eq. 2. The results of the last passes are shown in table 3.

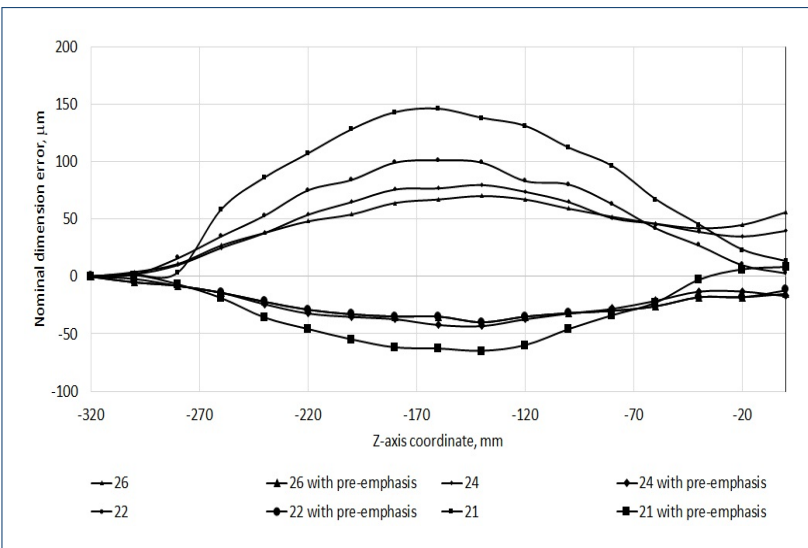

Figure 3 Comparison of errors in the diameters of workpieces and the tool trajectory when processing a plate Mitsubishi WNMG080404-MA

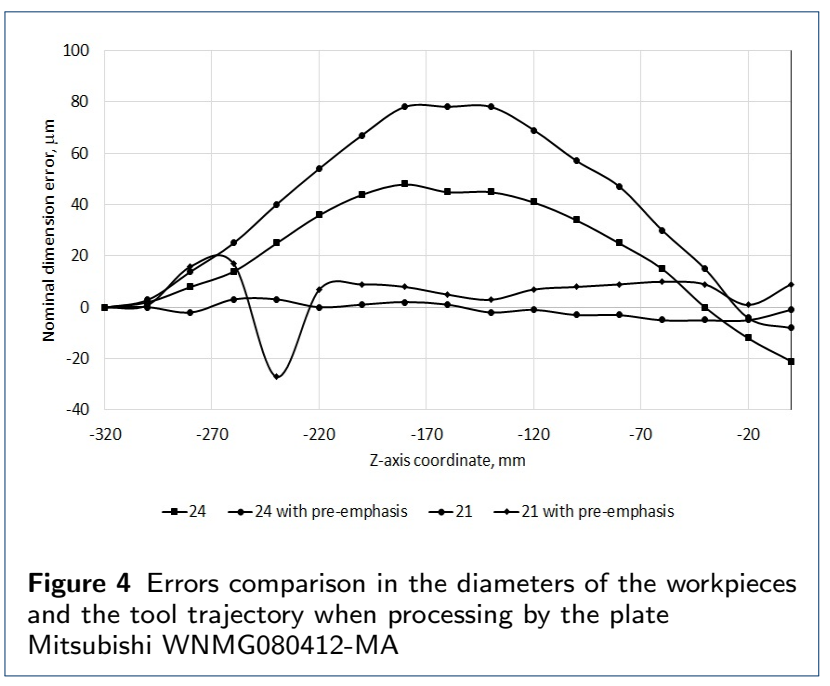

There are some significant deviations in the coordinates along the shaft length from -240 to $-280 \mathrm{~mm}$ of the predistorted trajectory along a diameter of $21 \mathrm{~mm}$ (table 3). The hardness difference was 3 HRC. The modes selected from the reference book [12] for a hardness of 35-36 HRC were incorrect for a hardness of $39 \mathrm{HRC}$, and therefore vibrations appeared. Such a point change of hardness is related to the technology violation during tempering. Similar vibrations occurred on the shafts with a hardness of more than $40 \mathrm{HRC}$ in various cutting conditions. The maximum error is $9 \mu \mathrm{m}$ without indications in coordinates from -240 to $-280 \mathrm{~mm}$. Figure 4 presents deviation distribution. Roughness after processing is no more than Ra 3,2 $\mu \mathrm{m}$. 


\section{Conclusion}

The research provides us with these results:

1 The efficiency of the mathematical model is confirmed when correcting the cutting depth.

2 Accuracy of processing is increased by more than $42 \%$ compared to the traditional processing method.

3 Roughness of at least grade 5 with a cutting depth of more than $1 \mathrm{~mm}$ is achieved.

\section{Availability of Data and Materials}

The datasets supporting the conclusions of this article are included within the article. Additional data obtained during the study is available by means of the reasonable request to the corresponding author.

Competing interests

The author declare that they have no competing interests.

Funding

Not applicable.

Author's contributions

AS was in charge of the whole analyses and wrote the manuscript. The author read and approved the final manuscript.

\section{Acknowledgements}

The author sincerely thanks to Dmitry Elkind and Vladimir Pegashkin from UrFU for study preparation, critical discussion and proofreading during manuscript preparation.

\section{Author Information}

Author born in 1987, is currently a seniour lecturer and training master on metalworking machine at Ural Federal University named after the first President of Russia B.N. Yeltsin (UrFU), Russia. He received his diplom of ingenereeng on mechanical engineering at the same university, in 2011. His research interests include shaft processing, optimization and automation of technological processes in mechanical engineering.

\section{References}

1. Mrozhek, J.A., Shaturov, G.F., Yasyukovich, E.I., G, S.D.: The study of accuracy in the processing of shafts in centers on lathes. Bulletin of BNTU. Series Metallurgy. Metalworking. Engineering 3, 30-34 (2006)

2. Phan, V., Baron, L., Mayer, R., Cloutier, G.: Finite element and experimental studies of diametral errors in cantilever bar turning. Applied Mathematical Modelling 27, 221-232 (2003). doi:10.1016/S0307-904X(02)00122-1

3. Swic, A., Wolos, D., Zubrzycki, J., Opielak, M., Gola, A., Taranenko, $\mathrm{V}$.: Accuracy control in the machining of low rigidity shafts. Applied Mechanics and Materials 613, 357-367 (2014). doi:10.4028/www.scientific.net/AMM.613.357

4. Swic, A., Wolos, D., Litak, G.: Method of control of machining accuracy of low-rigidity elastic-deformable shafts. Latin American Journal of Solids and Structures 11, 260-278 (2014). doi:10.1590/S1679-78252014000200007

5. Swic, A., Gola, A., Wołos, D., Opielak, M.: Micro-geometry surface modelling in the process of low-rigidity elastic-deformable shafts turning. Iranian Journal of Science and Technology, Transactions of Mechanical Engineering 41, 159-167 (2017). doi:10.1007/s40997-016-0050-4

6. Plotnikov, A.L., Chigirinsky, Y.L., Shmarov, A.A., Klyuykov, D.S. Precision control methods for processing non-rigid shafts on $\mathrm{cnc}$ lathes. In: Novakov, I.A. (ed.) Bulletin of Volgograd State Technical University. Ser.: Advanced Technologies in Mechanical Engineering vol. 3(100), pp. 39-43. Volgograd State Technical University, Volgograd (2012)

7. Plotnikov, A.L., Taube, A.O.: In: Control of Cutting Conditions on CNC Lathes. Polytechnic, Volgograd (2003)

8. Plotnikov, A.L., Taube, A.O.: Approach to ensure the required accuracy non-rigid shaft turning on numerical controlled machines. Scientific enquiry in the contemporary world: theoretical basics and innovative approach 4, 6-9 (2012)
9. Plotnikov, A.L., Mustafayev, E.I., Shmarov, A.A.: Problems of ensuring the calculated accuracy of turning in cad tp and methods for solving them. In: Novakov, I.A. (ed.) Bulletin of Volgograd State Technical University. Ser.: Advanced Technologies in Mechanical Engineering vol. 13(86), pp. 87-90. Volgograd State Technical University, Volgograd (2011)

10. Shelikhov, E., Chernousova, A., Vasilevykh, S.: Automatic correction control program method realization of the cnc machine tool under industrial conditions, pp. 1-5 (2017). doi:10.1109/ICIEAM.2017.8076166

11. Podporkin, V.G.: Processing of Non-rigid Parts. MASHGIZ, Moscow-Liningrad (1959)

12. Kosilova, A.G., Meshcheryakov, K.K.: Handbook of a Mechanical Enginee, Vol 2. Engineering, Moscow (1985)

13. Pegashkin, V.F., Pegashkina, E.V.: The Influence of Technological Parameters on the Shape Error of Parts. Study Guide. NTI (branch) UGTU-UPI, Nizhny Tagil (2007)

Tables 
Table 2 Deviation miscount of the form from the nominal size

\begin{tabular}{|c|c|c|c|c|c|c|c|c|c|c|c|c|c|c|c|c|c|c|c|c|}
\hline \multicolumn{21}{|c|}{ Cutting modes: $\mathrm{S}=0.15 \mathrm{~mm} / \mathrm{rev}, \mathrm{v}=100 \mathrm{~m} / \mathrm{min}, \mathrm{I}=320 \mathrm{~mm}$} \\
\hline Pass & Diameter, $\mathrm{mm}$ & $\mathrm{L} / \mathrm{D}$ & \multicolumn{17}{|c|}{ Coordinate, $\mu m$} & $\delta_{\max }$ \\
\hline \multirow[t]{2}{*}{1} & 26 & \multirow{2}{*}{12,31} & 0 & 4 & 11 & 27 & 38 & 48 & 54 & 64 & 67 & 70 & 67 & 59 & 52 & 46 & 42 & 45 & 56 & 70 \\
\hline & $26^{1}$ & & 0 & -5 & -8 & -14 & -22 & -29 & -33 & -35 & -35 & -40 & -35 & -32 & -30 & -26 & -18 & -18 & -15 & $40(-42 \%)$ \\
\hline 2 & $24^{1}$ & 13,33 & 0 & -2 & -8 & -14 & -24 & -32 & -35 & -37 & -42 & -43 & -37 & -32 & -28 & -21 & -13 & -13 & -17 & $43(-46 \%)$ \\
\hline \multirow{2}{*}{3} & 22 & \multirow{2}{*}{14,55} & 0 & 2 & 16 & 35 & 53 & 75 & 84 & 99 & 101 & 99 & 83 & 80 & 63 & 42 & 27 & 10 & 3 & 101 \\
\hline & $22^{1}$ & & 0 & -5 & -8 & -14 & -22 & -29 & -33 & -35 & -35 & -40 & -35 & -32 & -30 & -26 & -18 & -18 & -12 & $56(-45 \%)$ \\
\hline \multirow{2}{*}{4} & 21 & \multirow{2}{*}{15,24} & 0 & 1 & 3 & 58 & 86 & 107 & 128 & 143 & 146 & 138 & 131 & 112 & 96 & 67 & 45 & 23 & 13 & 146 \\
\hline & $21^{1}$ & & 0 & 1 & -7 & -19 & -35 & -46 & -55 & -62 & -63 & -65 & -60 & -46 & -34 & -23 & -3 & 6 & 8 & $73(-50 \%)$ \\
\hline
\end{tabular}

${ }^{1}$ with predistortion

Table 3 Deviation error of the form from the nominal size

\begin{tabular}{|c|c|c|c|c|c|c|c|c|c|c|c|c|c|c|c|c|c|c|c|c|}
\hline \multicolumn{21}{|c|}{ Cutting modes: $\mathrm{S}=0.2 \mathrm{~mm} / \mathrm{rev}, \mathrm{v}=100 \mathrm{~m} / \mathrm{min}, \mathrm{I}=320 \mathrm{~mm}, \mathrm{t}=1.5 \mathrm{~mm}$} \\
\hline Pass & Diameter, mm & $\mathrm{L} / \mathrm{D}$ & \multicolumn{17}{|c|}{ Coordinate, $\mu m$} & $\delta_{\max }$ \\
\hline \multirow[t]{2}{*}{1} & 24 & \multirow{2}{*}{13,33} & 0 & 2 & 8 & 14 & 25 & 36 & 44 & 48 & 5 & 5 & 41 & 34 & 25 & 15 & 0 & -12 & -21 & 71 \\
\hline & $24^{1}$ & & 0 & 0 & -2 & 3 & 3 & 0 & 1 & 2 & 1 & -2 & -1 & -3 & -3 & -5 & -5 & -5 & -1 & $13(-81 \%)$ \\
\hline 2 & $21^{1}$ & 15,24 & 0 & 1 & 16 & 17 & -27 & 7 & 9 & 8 & 5 & 3 & 7 & 8 & 9 & 10 & 9 & 1 & 9 & $44(-49 \%)$ \\
\hline
\end{tabular}

${ }^{1}$ with predistortion 
Figures

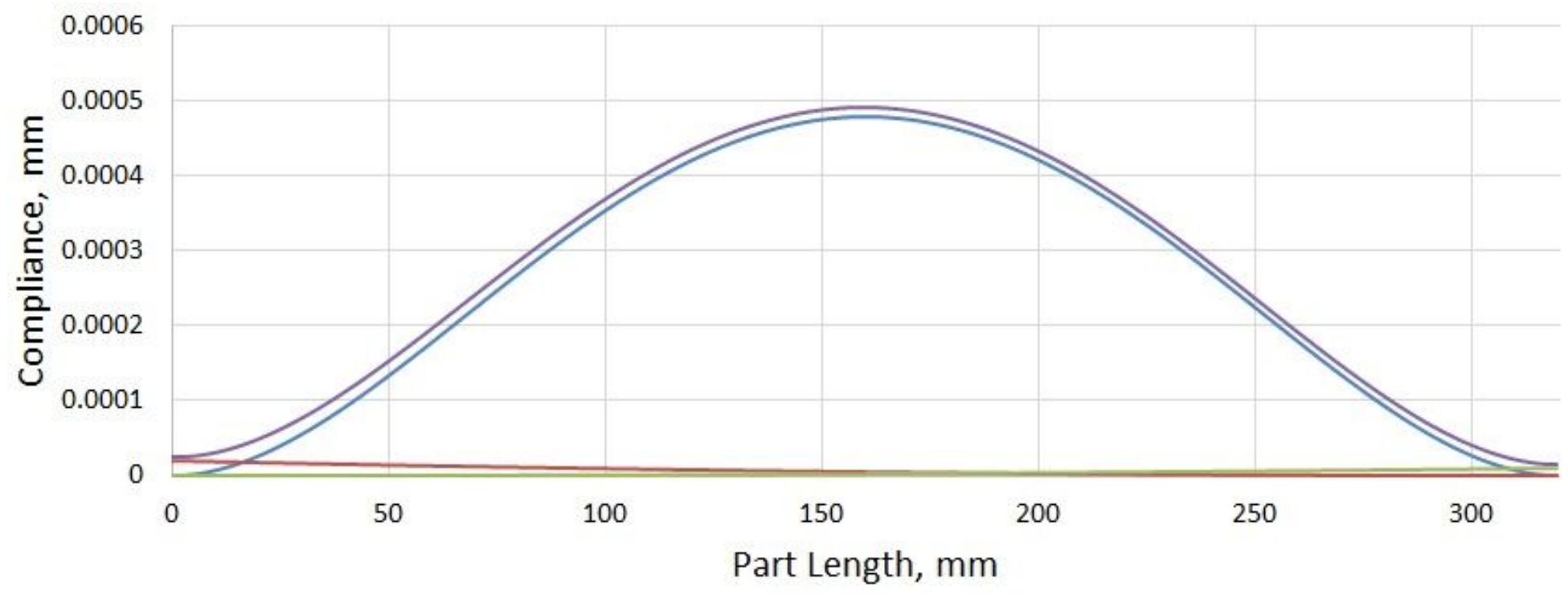

- Caliper deformation - Headstock deformation

—Tailstock Deformation —Total Deformation

Figure 1

The schedule of deformations and exibility of the technological system

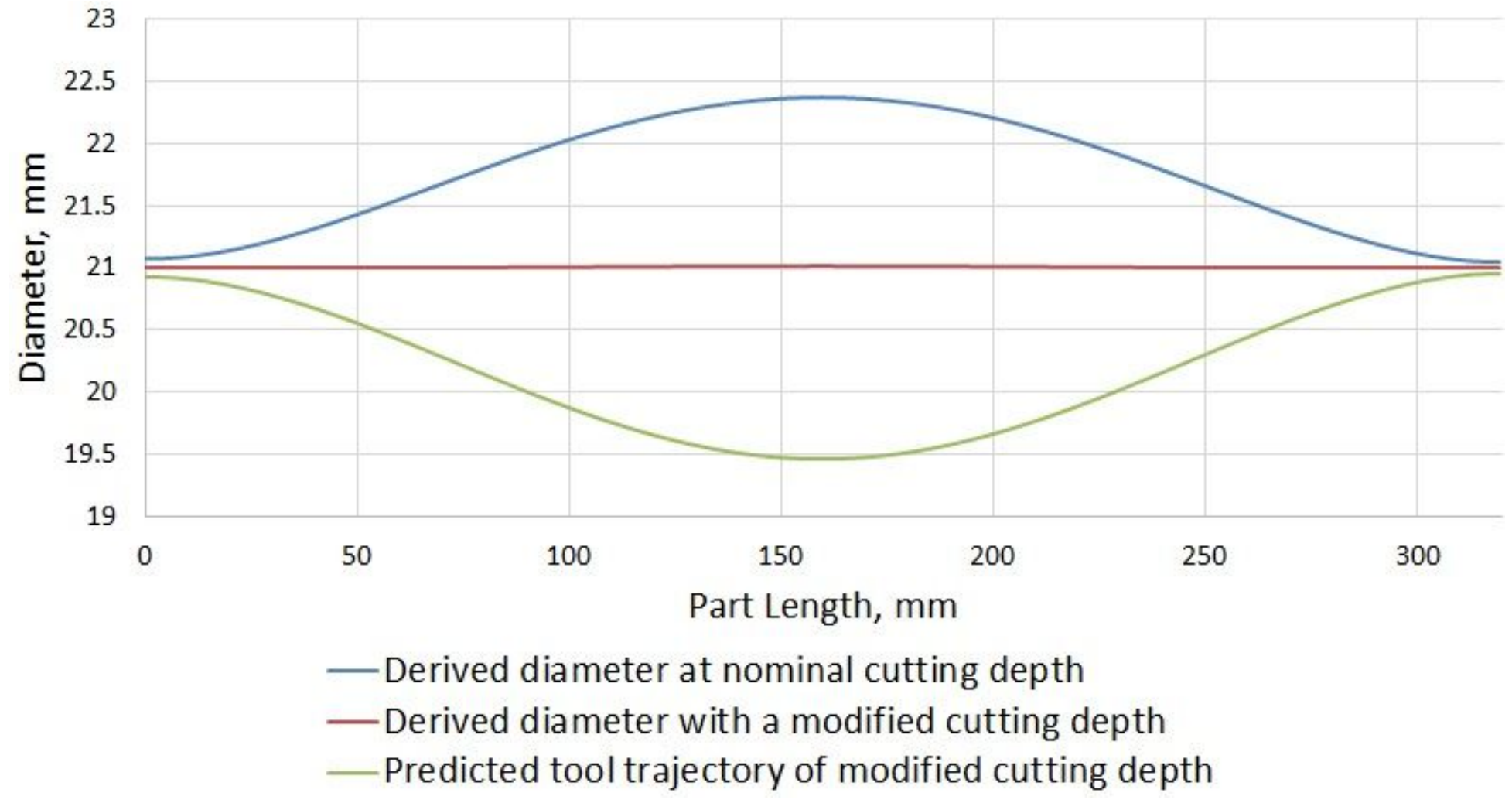

Figure 2 
Comparison of the diameters obtained and the trajectory of the tool motion according to the mathematical model

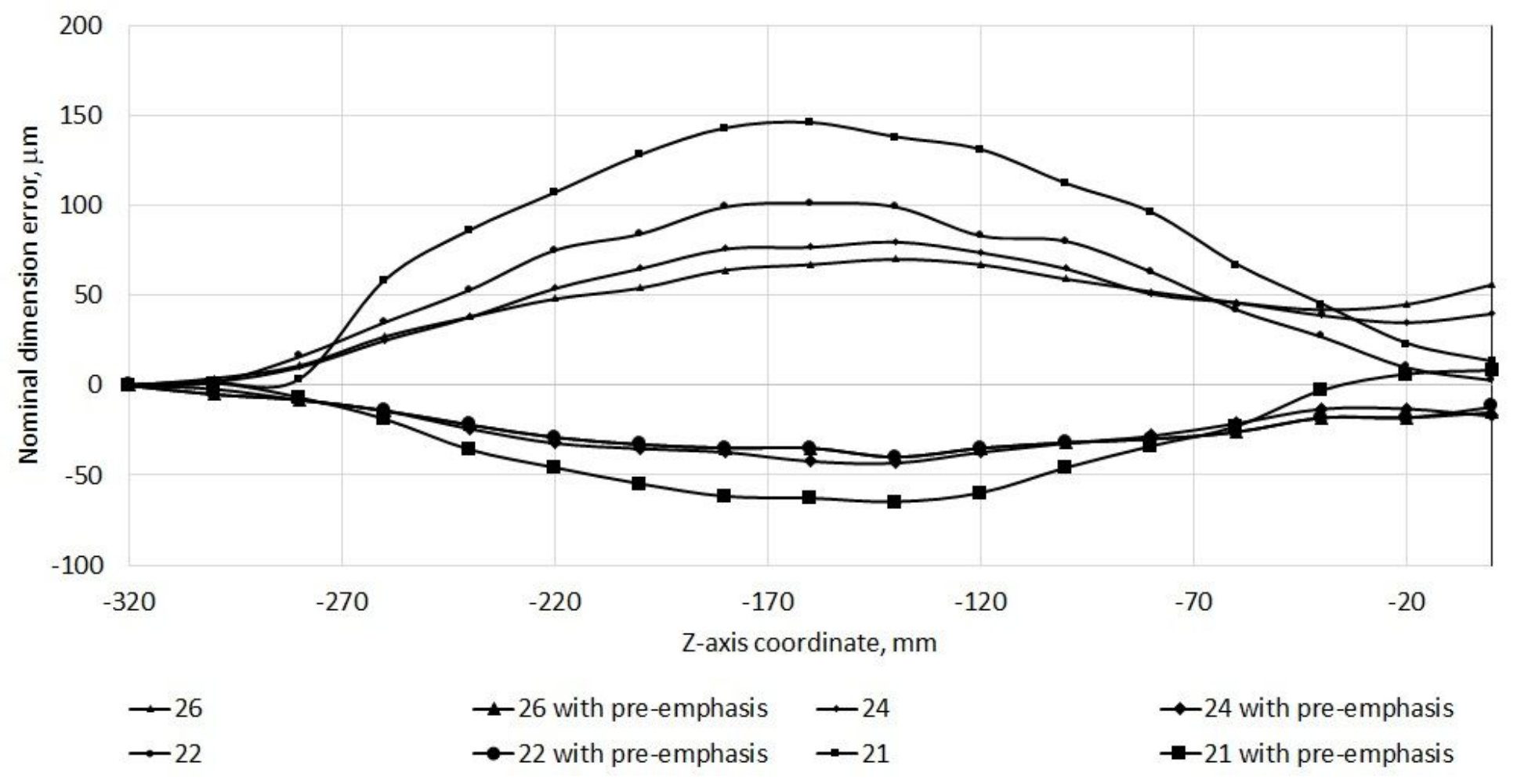

\section{Figure 3}

Comparison of errors in the diameters of workpieces and the tool trajectory when processing a plate Mitsubishi WNMG080404-MA 


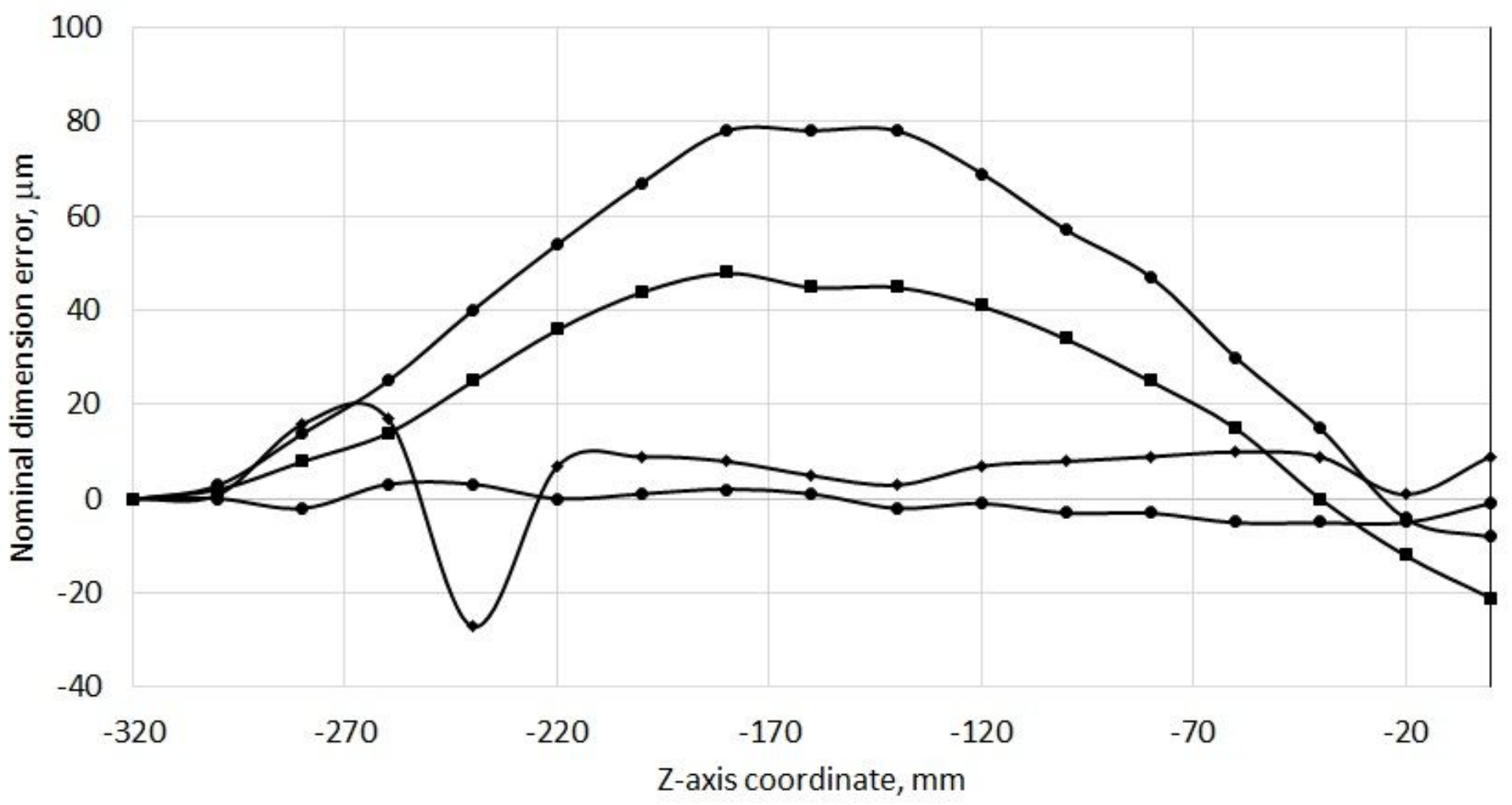

$\rightarrow-24 \rightarrow 24$ with pre-emphasis $\rightarrow-21 \rightarrow-21$ with pre-emphasis

\section{Figure 4}

Errors comparison in the diameters of the workpieces and the tool trajectory when processing by the plate Mitsubishi WNMG080412-MA 